\title{
DISTRIBUTION OF RADIOMERCURY ADMINISTERED AS LABELLED CHLORMERODRIN (NEOHYDRIN`) IN THE KIDNEYS OF RATS AND DOGS ${ }^{1}$
}

\author{
BY ROGER L. GREIF, W. JAMES SULLIVAN, GLORIA S. JACOBS, AND \\ ROBERT F. PITTS
}

(From the Department of Physiology, Cornell University Medical College, New York, N. Y.)

(Submitted for publication August 8, 1955; accepted September 7, 1955)

Although the mechanism by which mercurial diuretics exert their effect is still obscure, the experiments of Bartram (1) strongly favor direct renal action. Further studies have shown that following administration of such compounds to humans and to animals a higher concentration of mercury is found in the kidney than in the other tissues examined, $(2,3)$ and it appears that renal binding precedes the onset of diuresis $(4,5)$. A number of such investigations have been carried out with the use of diuretics labelled with $\mathrm{Hg}^{203}$ $(2,3)$, and this isotope administered as $\mathrm{HgCl}_{2}$ has been found by radioautographic means in high concentration in the renal cortex of rats (6).

The experiments to be reported consist of a detailed study of the gross and subcellular localization of radiomercury administered as labelled Neohydrin (7) in the kidneys of rats. The distribution was also examined in the kidneys of dogs sacrificed at the time of maximum diuresis.

PART I. RAT TISSUE STUDIES

\section{Method}

Two hundred gram female albino rats received intramuscular injections of Neohydrin(i) labelled with radiomercury and were sacrificed by exsanguination under light ether anesthesia. The kidneys were removed, decapsulated, and weighed, and the tissue so obtained was minced with scissors. The mince was ground in cold $0.25 \mathrm{M}$ sucrose by means of a motor-driven homogenizer with "Teflon" pestle, and sufficient sucrose was added to make a 10 per cent $w / v$ suspension. Portions of this material were subjected to differential centrifugation by modifications of the method of Schneider (8).

The "nuclear" fraction was isolated by centrifugation at $600 \times \mathrm{g}$ for 10 minutes in an I.E.C. centrifuge with No. 233 head. The precipitate from this step was twice resuspended and recentrifuged in $0.25 \mathrm{M}$ sucrose, as men-

1 This investigation was supported by a research grant from the National Institute of Arthritis and Metabolic Diseases of the National Institutes of Health, Bethesda, Md. tioned above. The final residue, resuspended in sucrose, constituted the "nuclear" fraction.

The pooled supernatant fluids from the nuclear isolation and washes were centrifuged at $25,000 \times g$ for one hour in a Servall SS angle centrifuge. The pellet from this operation was resuspended in sucrose and again centrifuged at $25,000 \times \mathrm{g}$ for one hour. The resuspended precipitate constituted the "granular" fraction. In certain experiments, "large granules" were isolated by centrifugation of the supernatant fluid from the nuclear isolation at $8500 \times \mathrm{g}$ for ten minutes. The supernatant fluid from this step was centrifuged at $25,000 \times \mathrm{g}$ for one hour to yield a "small granule" pellet.

The fluid which remains after removal of the solids sedimentable at $25,000 \times \mathrm{g}$ for one hour is the "soluble" fraction. In a few instances only "precipitate" and "soluble" are mentioned. These terms refer to the sediment and the supernatant fluid from a single centrifugation of 10 per cent suspension at $25,000 \times \mathrm{g}$ for one hour.

All separation operations were carried out at $4^{\circ} \mathrm{C}$. The pellets were resuspended in a tissue grinder for sucrose washings. Fractions were carefully checked by phase microscopy. Radioactivity was measured in a $\mathrm{Nu}$ clear Instrument well-type scintillation counter with No. 163 scaling unit. Nitrogens were determined by means of a titrimetric semimicro Kjeldahl method using a mercury catalyst.

\section{Results}

Table I and Figure 1 summarize the relationship between the mercury and nitrogen content of the kidney fractions obtained from rats. Despite variation both in the amount of mercurial diuretic administered and the time of sacrifice of the animal, the largest amount of mercury per milligram of nitrogen was consistently found in the "soluble" fraction. The ratio of the amount of mercury in the soluble fraction per milligram of nitrogen to the amount of mercury in the "total" suspension per milligram, here designated as the $\mathrm{S} / \mathrm{T}$ ratio, remains quite constant at all dosage levels tested.

In separate experiments, "soluble" fraction from 


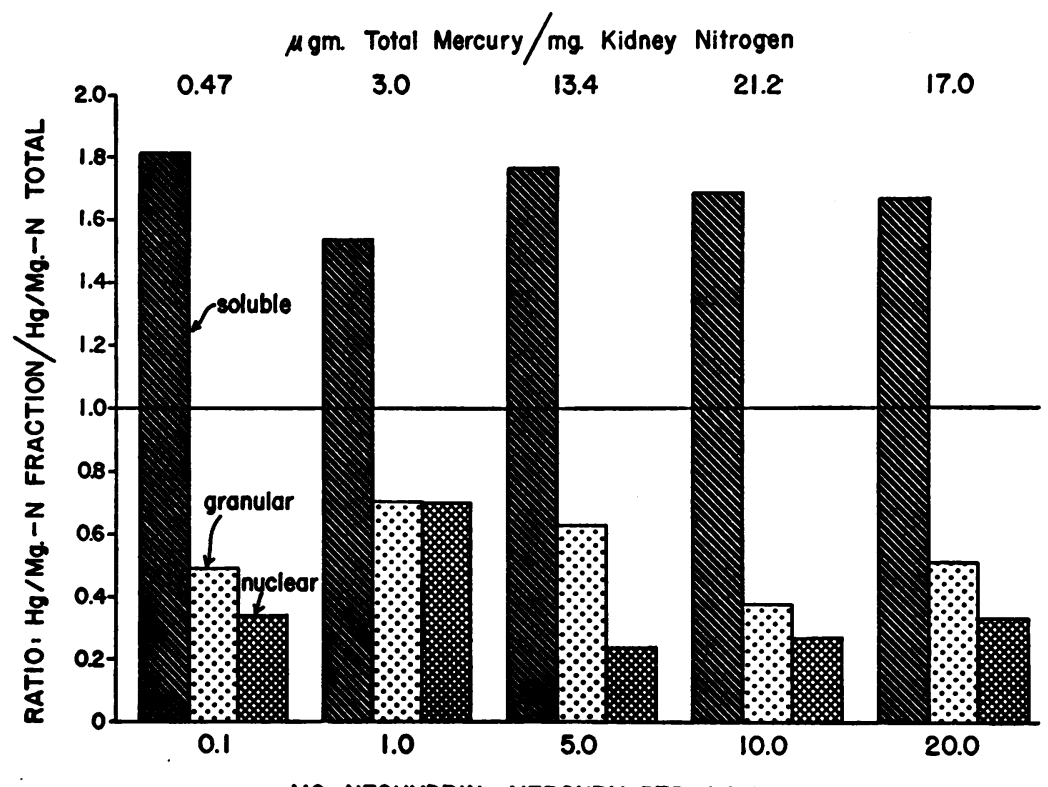

MG. NEOHYDRIN - MERCURY PER KGM.

Fig. 1. Relationship between Mercury Concentration in Kidney Fractions and Whole Kidney following Administration of Increasing Amounts of Chlormerodrin

the kidneys of animals which had received 10 mg. radiomercury per kilo was centrifuged at $105,000 \times \mathrm{g}$ for one hour in the Spinco Model G preparative centrifuge with negligible sedimentation of radioactivity. Preliminary experiments indicate that the mercury remains firmly bound to the "soluble" fraction during dialysis against $\mathrm{pH} 8.6$ barbital buffer 0.1 ionic strength, and that most of it is precipitated when this kidney fraction is brought to half saturation with ammonium sulfate.

In all but one of the series of experiments the amount of mercury bound to the "granular" fraction, based on nitrogen, is higher than that in the "nuclear" fraction. An experiment was performed in which the "granular fraction" was isolated from the kidneys four hours following the administration of $1 \mathrm{mg}$. radiomercury as Neohydrin to rats. This fraction was repeatedly washed with sucrose. The once-washed starting material contained 1.78 micrograms mercury per milligram nitrogen, and the figures for four washes and seven washes were respectively 1.74 and 1.80 micrograms per milligram nitrogen.

TABLE I

Micrograms radiomercury per milligram nitrogen in rat kidney fractions

\begin{tabular}{|c|c|c|c|c|c|c|c|c|c|}
\hline \multirow{2}{*}{$\underset{m g . / K}{\text { Dose }}$} & \multirow{2}{*}{$\begin{array}{c}\text { Sacrifice } \\
\text { time }\end{array}$} & \multirow{2}{*}{$\begin{array}{l}\text { Number } \\
\text { animals }\end{array}$} & \multirow[b]{2}{*}{ "Total" } & \multirow[b]{2}{*}{ "Nuclei" } & \multirow[b]{2}{*}{ Granules } & \multirow[b]{2}{*}{ Soluble } & \multicolumn{2}{|c|}{ Recovery } & \multirow{2}{*}{$\begin{array}{l}\text { Ratio } \\
\text { S/T }\end{array}$} \\
\hline & & & & & & & Nitrogen & Mercury & \\
\hline $\begin{array}{c}0.1 \\
1 \\
1 \\
5 \\
10 \\
20\end{array}$ & $\begin{array}{l}4 \\
4 \\
4 \\
4 \\
4 \\
4\end{array}$ & $\begin{array}{l}3 \\
1 \\
2 \\
6 \\
6 \\
6\end{array}$ & $\begin{array}{r}.47 \\
4.2 \\
3.0 \\
13.4 \\
21.2 \\
17.0\end{array}$ & $\begin{array}{l}.16 \\
2.7 \\
2.1 \\
3.2 \\
5.8 \\
5.6\end{array}$ & $\begin{array}{l}.23 \\
4.3 \\
2.1 \\
8.2 \\
8.1 \\
8.7\end{array}$ & $\begin{array}{c}.85 \\
6.4 \\
4.6 \\
23.6 \\
35.6 \\
28.3\end{array}$ & $\begin{array}{c}97.5 \\
92.5 \\
95 \\
102 \\
101.4 \\
97.6\end{array}$ & $\begin{array}{l}96.2 \\
96.5 \\
89.9 \\
96.5 \\
94.5 \\
93.5\end{array}$ & $\begin{array}{l}1.81 \\
1.52 \\
1.53 \\
1.76 \\
1.68 \\
1.67\end{array}$ \\
\hline \multicolumn{10}{|c|}{ Precipitate } \\
\hline $\begin{array}{l}1 \\
1\end{array}$ & $\begin{array}{l}1 \\
4\end{array}$ & $\begin{array}{l}1 \\
1\end{array}$ & $\begin{array}{l}3.3 \\
3.6\end{array}$ & & & $\begin{array}{l}4.9 \\
6.4\end{array}$ & $\begin{array}{c}93.5 \\
100\end{array}$ & $\begin{array}{r}93 \\
102\end{array}$ & $\begin{array}{l}1.48 \\
1.78\end{array}$ \\
\hline
\end{tabular}


PART II. DOG TISSUE STUDIES

\section{Method}

Three technically adequate experiments were performed on mongrel female dogs weighing 14 to $21 \mathrm{Kg}$. After anesthesia was induced with sodium pentobarbital (not more than $30 \mathrm{mg}$. per $\mathrm{Kg}$.), an indwelling catheter was inserted. Isotonic sodium chloride was infused at 5 $\mathrm{ml}$. per min. throughout the experiment. Urine flow became stable $1 \frac{1}{2}$ to 2 hours after starting the infusion. At this time $\mathrm{Hg}^{208}$-Neohydrin (1 $\mathrm{mg}$. $\mathrm{Hg}$ per $\mathrm{Kg}$.) was given as a single intravenous injection. Urine was collected at 10 to 15-minute intervals until it appeared that urine flow had attained a maximum. The dog was then sacrificed with an overdose of pentobarbital. The kidneys were removed, decapsulated and weighed. Subsequent procedures were carried out at $4^{\circ} \mathrm{C}$. One-quarter of one kidney was homogenized in a motor-driven tissue grinder using a "Teflon" pestle. The bulk of the remaining tissue was separated into cortex, outer medulla, and inner medulla. ${ }^{2}$ These samples were also homogenized by machine. All homogenates were made up with 0.25 $M$ sucrose to a suspension containing 10 grams of tissue per $100 \mathrm{ml}$. of solution.

The schema of differential centrifugation employed with the dog kidneys was in general similar to that described for the rat kidney fractionations.

For the study of the-intrarenal distribution of radiomercury a kidney was sectioned parasagittally and a cylindrical core was obtained by passing a sharp corkborer through the kidney along an axis normal to the surface and traversing a medullary pyramid. This core was cut free-hand into 10 to 12 sections which were transferred to tared counting tubes for the determination of $\mathrm{Hg}^{\mathrm{m}}$ activity. In one core nitrogen was determined and a small fragment of each section fixed and stained for histologic study.

\section{Results}

In Table II are presented data depicting the distribution of $\mathrm{Hg}^{203}$ in various regions of the kidney, as well as its distribution in subcellular fractions of kidney cortex. It is apparent that the mercury concentration in the cortex is greater than its average concentration in the whole kidney. The cortex/whole kidney concentration ratio averages 1.7. Similar data on the distribution of mercury in outer and inner medulla indicate that

\footnotetext{
2 In this experiment the outermost zone of the kidney was considered to be "cortex." This tissue was dark red and granular in appearance and contained some medullary rays. The "outer medulla" consisted of pale striated medullary pyramids, but also included much cortical tissue occurring between these pyramids in columns. The "inner medulla" consisted largely of pale fibrous papillary tissue.
}

the mercury concentration in these regions is consistently lower than it is in the cortex. The cortex/outer medulla and cortex/inner medulla ratios averaged 9 and 16 , respectively.

Data obtained from subcellular fractions separated by differential centrifugation reveal that the mercury is most highly concentrated in the soluble component. In the three experiments in Table II, the soluble/total ratio of mercury concentration averaged 1.59. In two experiments in which a similar fractionation of outer and inner medulla was carried out, the soluble/total ratios averaged 1.67 and 1.54 , respectively.

The mercury concentration in sections cut from a cylindrical core of dog kidney is depicted in Figure 2. In this figure, the units on the abscissa represent the number of sections starting from the surface of the kidney, and thus correspond to distance from the kidney surface measured in arbitrary units. The region from which each section was taken, as judged by gross inspection and histologic examination, is indicated at the top of the figure. It is clear that the mercury is most highly concentrated in the outer cortex. The concentration falls very rapidly in the outer region of the medulla, and attains its lowest levels-scarcely higher than that of plasma-in the inner medulla. The mercury concentration in plasma samples drawn just prior to removal of the kidneys averaged 0.74 micrograms per milliliter.

\section{DISCUSSION}

The above results are an extension of the work of others who have demonstrated that the mercury in a mercurial diuretic is found in highest concentration in the kidney $(2,3)$.

The progressive decrease of mercury concentration from a maximum in the outer cortex to a minimum value in the medullary papilla is in accord with the radiographic studies of Lippman, Finkle, and Gillette (6) previously cited. The affinity of mercury for sulfhydryl groups is well established (9); it is therefore not surprising that the intrarenal distribution of mercury observed in our experiments correlates reasonably well with the distribution of protein-bound sulfhydryl groups established by histochemical studies (10). However, such groups are present in comparable concentration in other tissues (myocardium, skeletal 


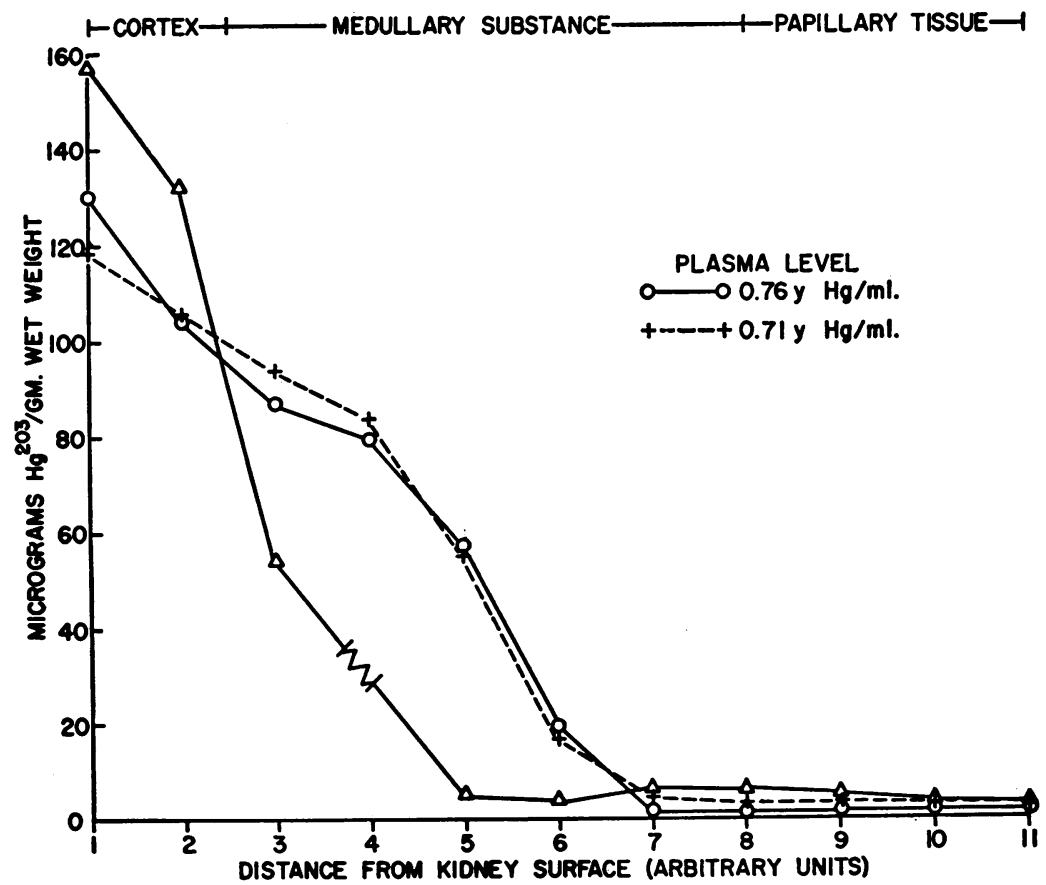

Fig. 2. Relation between Mercury Concentration and Distance from Kidney Surface of Serial Segments of Renal Tissue

muscle) which bind much less radiomercury; hence, factors unique to the kidney must be involved.

The results of the studies of the apparent intracellular distribution of mercury can be interpreted in several ways. The large amount of mercury in the soluble fraction is most readily explained by the presence in this fraction of mercurybinding proteins in high concentration. The relatively constant $S / T$ ratio over a wide dosage range suggests that the capacity of these proteins to bind mercury has not been exceeded with the largest amount of diuretic employed. The observed decrease in mercury content of the kidneys following the administration of amounts of the diuretic in excess of $10 \mathrm{mg}$. per kilo suggests that the limiting factors are related to toxic effects, possibly cardiovascular, to the animal rather than to the inability of these proteins to bind additional mercury. In our studies there is no evidence for or against concentration of the mercury in the soluble fraction by means of an active process. In the interpretation of these findings caution must be exercised in relating to in vivo conditions the results of localization studies carried out on diluted suspensions of broken cells.

Mercurial diuresis is presumed to occur through inhibition of reabsorption of water and electrolytes in the convoluted tubules, although the problem of whether the locus of action is primarily on the proximal or distal portion has not yet been settled (11). The tubular structures in question predominate in the regions of highest radiomercury concentration. Histochemical techniques have re-

TABLE II

Micrograms radiomercury per milligram nitrogen in fractions obtained from kidneys of dogs sacrificed during diuresis from $1 \mathrm{mg}$. $\mathrm{Hg}^{203}$ per kilo given as Neohydrin ${ }^{\circledR}$ intravenously

\begin{tabular}{|c|c|c|c|c|c|c|c|}
\hline \multirow{2}{*}{$\begin{array}{c}\text { Sacrifice } \\
\text { time } \\
\text { min. }\end{array}$} & \multirow{2}{*}{$\begin{array}{l}\text { Whole } \\
\text { kidney }\end{array}$} & \multicolumn{3}{|c|}{ Cortex } & \multicolumn{3}{|c|}{ Recovery } \\
\hline & & Total & Precipitate & Soluble & Nitrogen & Mercury & $\mathrm{S} / \mathrm{T}$ ratio \\
\hline $\begin{array}{l}105 \\
120 \\
120\end{array}$ & $\begin{array}{l}1.9 \\
3.26 \\
3.54\end{array}$ & $\begin{array}{l}2.9 \\
5.5 \\
6.4\end{array}$ & $\begin{array}{l}1.4 \\
2.8 \\
3.0\end{array}$ & $\begin{array}{r}4.6 \\
8.9 \\
10.7\end{array}$ & $\begin{array}{c}100 \\
98.2 \\
102\end{array}$ & $\begin{array}{l}96.3 \\
96.2 \\
101\end{array}$ & $\begin{array}{l}1.57 \\
1.62 \\
1.57\end{array}$ \\
\hline
\end{tabular}


cently been used to demonstrate a high concentration of succinic dehydrogenase in this same outer cortical region $(12,13)$. Since toxic concentrations of mercurial diuretics are required to produce visible changes in enzyme activity, currently available histochemical techniques offer no solution to the question of the relationship between succinic dehydrogenase inhibition and the action of these substances in pharmacological amounts. Handley and Lavik (14) have reported an inhibition of succinoxidase activity determined manometrically in homogenates of the kidneys of rats and dogs after these animals had received a diuretic dose of an organic mercurial. Other workers have been unable to produce such inhibition, and could neither produce diuresis with the use of other inhibitors of this enzyme system nor implicate the system through sequential blocking techniques $(15,16)$.

The demonstration of radiomercury in both the "soluble" and the "granular" fractions relates to this problem only in that mercury seems firmly bound to the structures which are believed to be important in the process of ion transport $(17,18)$. Succinoxidase is only one of the many enzyme systems associated with the mitochondria included in our "granular" fraction (19).

Cohen, DeGroot, and Weber $(20,21)$ have recently demonstrated that diuretic amounts of organic mercurials inhibit both the formation and the breakdown of energy-rich phosphate compounds in slices of rat kidney. Slices were used because this inhibition could not be shown with preparations of mitochondria washed with potassium chloride, and the suggestion was made that washing removed the mercurial diuretic from these structures (22). Our results indicate that the mercury is firmly bound to granules washed with sucrose, and if such a preparation should also fail to demonstrate inhibition, some other explanation must be given for his findings. It seems possible that the high concentration of mercury in the "soluble" fraction, which would be removed during the isolation of mitochondria, may be important in the inhibition process.

\section{SUMMARY}

Chlormerodrin labelled with $\mathrm{Hg}^{203}$ was administered intramuscularly to rats in amounts rang- ing from $0.1 \mathrm{mg}$. to $20 \mathrm{mg}$. mercury per kilo body weight. Fractions of sucrose suspended kidney homogenate were obtained by differential centrifugation. The highest concentration of mercury was in the "soluble" fraction. Mercury was also present in granules which could not be removed by repeated washing.

Dogs were sacrificed at the time of maximum diuresis due to labelled chlormerodrin. The highest concentration of mercury was found in the outer renal cortex, with diminishing radioactivity as the medullary papillae were approached. The intracellular distribution of mercury in dog kidney homogenates resembled that of rat kidney.

\section{REFERENCES}

1. Bartram, E. A., Experimental observations on the effect of various diuretics when injected directly into one renal artery of the dog. J. Clin. Invest., 1932, 11, 1197.

2. Milnor, P., Burch, G., Ray, T., Threefoot, S., and Berenson, G., Considerations of renal, hepatic, and extremital arteriovenous differences in concentration of radiomercury of a mercurial diuretic. J. Clin. Invest., 1950, 29, 72.

3. Aikawa, J. K., The renal localization of $\mathrm{Hg}^{\mathrm{me}}$ administered as tagged mercaptomerin. Clin. Res. Proc., 1955, 3, 135.

4. Burch, G., Ray, T., Threefoot, S., Kelly, F. J., and Svedberg, A., The urinary excretion and biologic decay periods of radiomercury labeling a mercurial diuretic in normal and diseased man. $\mathrm{J}$. Clin. Invest., 1950, 29, 1131.

5. Weston, R. E., Grossman, J., Lehman, R. A., Ullmann, T. D., Halperin, J. P., and Leiter, L., Renal extraction and excretion of mercury in man following intravenously administered mercurial diuretics. J. Clin. Invest., 1951, 30, 1221.

6. Lippman, R. W., Finkle, R. D., and Gillette, D., Effect of proteinuria on localization of radiomercury in rat kidney. Proc. Soc. Exper. Biol. \& Med., 1951, 77, 68.

7. Borghgraef, R. R. M., and Pitts, R. F., The distribution of chlormerodrin (Neohydrin $(8)$ in tissues of the rat and dog. J. Clin. Invest., 1956, 35, 31.

8. Schneider, W. C., Intracellular distribution of enzymes. III. The oxidation of octanoic acid by rat liver fractions. J. Biol. Chem., 1948, 176, 259.

9. Barron, E. S. G., Thiol groups of biological importance. Advances in Enzymology, 1951, 11, 201.

10. Barrnett, R. J., and Seligman, A. M., Histochemical demonstration of sulfhydryl and disulfide groups of proteins. J. Nat. Cancer Inst., 1954, 14, 769. 
11. Pitts, R. F., and Sartorius, O. W., Mechanism of action and therapeutic use of diuretics. Pharmacol. Rev., 1950, 2, 161 in J. Pharmacol. \& Exper. Therap., 1950, 98.

12. Rennels, E. G., and Ruskin, A., Histochemical changes in succinic dehydrogenase activity in rat kidney following administration of mercurial diuretics. Proc. Soc. Exper. Biol. \& Med., 1954, 85, 309.

13. Wachstein, M., and Meisel, E., Influence of experimental renal damage on histochemically demonstrable succinic dehydrogenase activity in the rat. Am. J. Path., 1954, 30, 147.

14. Handley, C. A., and Lavik, P. S., Inhibition of the kidney succinic dehydrogenase system by mercurial diuretics. J. Pharmacol. \& Exper. Therap., 1950, $100,115$.

15. Fawaz, G., and Fawaz, E. N., Mechanism of action of mercurial diuretics. Proc. Soc. Exper. Biol. \& Med., 1951, 77, 239.

16. Fawaz, G., and Fawaz, E. N., Mechanism of action of mercurial diuretics II. Proc. Soc. Exper. Biol. \& Med., 1954, 87, 30.
17. Bartley, W., Davies, R. E., and Krebs, H. A., Active transport in animal tissues and subcellular particles. Proc. Roy. Soc., London, Series B, 1954, 142, 187.

18. Mudge, G. H., Renal mechanisms of electrolyte transport in Ion Transport Across Membranes, Clarke, H. T., Ed., New York, Academic Press, 1954, p. 75.

19. Schneider, W. C., Biochemical constitution of mammalian mitochondria. J. Histochem. \& Cytochem., 1953, 1, 212.

20. Cohen, E. M., DeGroot, C. A., and Weber, J. F., The influence of mersalyl on phosphate metabolism in kidney slices from intravenously injected rats. Acta Physiol. Pharmacol. Neerl., 1954, 3, 512.

21. Cohen, E. M., DeGroot, C. A., and Weber, J. F., Influence of mersalyl on phosphate metabolism in kidney slices of intramuscularly injected rats. Acta Physiol. Pharmacol. Neerl., 1955, 4, 1.

22. Cohen, E. M., On the mechanism of action of mercurial diuretics. Acta Physiol. Pharmacol. Neerl., 1953, 3, 45. 